\title{
ACESSO À JUSTIÇA E POVOS INDÍGENAS
}

Daize Fernanda Wagner ${ }^{1}$

\section{RESUMO}

Discute o acesso à justiça aos indígenas após a promulgação da Constituição da República Federativa do Brasil de 1988 (CF/88), sobretudo a partir da previsão estabelecida em seu artigo 232. Para tanto, parte do problema: em que medida o direito à diferença dos Povos Indígenas se efetiva no acesso à justiça no Brasil? Aborda o acesso à justiça dos vulneráveis, na perspectiva adotada nas 100 Regras de Brasília sobre Acesso à Justiça das Pessoas em Condição de Vulnerabilidade e o relaciona às conquistas jurídicas dos indígenas após a $\mathrm{CF} / 88$. A metodologia utiliza abordagem qualitativa, baseada em pesquisa bibliográfica e documental.

\section{PALAVRAS-CHAVE}

Acesso à Justiça; Povos Indígenas; 100 Regras de Brasília; Legitimidade Processual; Constituição de 1988.

\section{ACESS TO JUSTICE AND THE INDIGENOUS PEOPLE}

\begin{abstract}
It discusses the access to justice to the indigenous peoples after the promulgation of the Federation Republic of Brazil of 1988 (CF/88), especially from the prevision established in its article 232. Therefore, part of the problem: how effective is the right to difference of the indigenous peoples in the access to justice in Brazil? It deals with the access to justice of minorities, into the perspective adopted in the 100 Brasília's rules on the access to Justice of the Persons in Vulnerability Status and it is related to legal achievements of the indigenous peoples after $\mathrm{CF} / 88$.
\end{abstract}

The qualitative approach is the methodology proposed, based on document bibliographical review.

\footnotetext{
${ }^{1}$ Professora Adjunta no curso de Direito e Colaboradora no Programa de Pós-Graduação em Estudos de Fronteira da Universidade Federal do Amapá. Doutora em Direito (UFMG). Mestre em Direito (LMU/Alemanha). Email: daizefernandawagner@gmail.com
} 


\section{KEYWORDS}

Access to Justice; Indigenous Peoples; 100 Brasília's rules; Legitimacy Proceeding; Constitution of 1988.

\section{INTRODUÇÃO}

O presente artigo objetiva discutir o acesso à justiça aos Povos Indígenas após a promulgação da Constituição da República Federativa do Brasil de 1988 (CF/88), sobretudo a partir da previsão estabelecida em seu artigo 232, que afirma que "os índios, suas comunidades e organizações são partes legítimas para ingressar em juízo em defesa de seus direitos e interesses, intervindo o Ministério Público em todos os atos do processo.” (BRASIL, 1988). Para tanto, parte do seguinte problema: em que medida o direito à diferença dos Povos Indígenas se efetiva no acesso à justiça no Brasil?

Tem-se como hipótese que o acesso à justiça dos indígenas, tanto individualmente, quanto coletivamente, a despeito da previsão expressa no art. $232 \mathrm{da} \mathrm{CF/88,} \mathrm{demandou} \mathrm{tempo}$ para que fosse paulatinamente assegurado perante o Poder Judiciário. Tal direito fundamental tem sido efetivado, em grande medida, pelo protagonismo dos próprios indígenas e suas organizações. O Poder Judiciário, em parte, se abre à diversidade. Todavia, tal abertura ainda requer melhor compreensão por parte dos integrantes do Poder Judiciário acerca do direito à diferença dos Povos Indígenas, assegurado na CF/88 e na Convenção n. 169 sobre Povos Indígenas e Tribais da Organização Internacional do Trabalho (Convenção 169 da OIT).

$\mathrm{O}$ acesso à justiça, numa perspectiva mais tradicional, sempre esteve relacionado às dificuldades de ingresso no Judiciário por razões de hipossuficiência econômica, de informação e de assistência especializada. Posteriormente, passou a estar relacionado às dificuldades de saída do Judiciário, ou seja, às discussões sobre a razoável duração do processo e a celeridade.

$\mathrm{O}$ acesso à justiça demanda que se discuta também tal direito fundamental aos vulneráveis, cujas barreiras de acesso ao Judiciário são ainda maiores. No que se refere aos indígenas, as dificuldades de acesso à justiça estão em muito relacionadas à sua vulnerabilidade. Embora não haja um conceito legal para o que seja vulnerabilidade, no caso dos indígenas, pode-se afirmar que ela tem relação com vários fatores, como diferenças culturais e linguística e o próprio fato de representarem uma expressiva minoria quando considerada toda a população brasileira. $^{2}$

\footnotetext{
${ }^{2}$ Os indígenas são minoria númerica, pois representam apenas 0,4\% de toda a população nacional (IBGE, 2012). Além disso, e de maneira mais relevante, são minoria em virtude de sua relativa exclusão das instâncias de poder
} 
Além disso, sua vulnerabilidade também está associada ao tipo de questões que trazem ao Poder Judiciário, que lhe são muito peculiares: corriqueiramente, referem-se a todo um grupo ou povo e têm relação com acesso e permanência em suas terras.

A vulnerabilidade dos indígenas também se acentua quando se observa contra quem litigam: não raro, seus interesses chocam-se com os interesses de grandes detentores de capital, como é o caso de mineradoras ou de produtores rurais. Outras vezes, é o próprio Estado que se torna seu maior algoz, por não zelar pela efetividade dos direitos dos Povos Indígenas através de políticas indigenistas adequadas.

Apenas a partir da promulgação da CF/88, é que os Povos Indígenas passaram a ter seu direito à diferença reconhecido em âmbito constitucional. Esta foi a primeira constituição brasileira que destinou um capítulo inteiro para tratar dos direitos dos Povos Indígenas, além de fazê-lo também em vários dispositivos esparsos. Também se destaca a Convenção 169 da OIT, ratificada pelo Brasil no ano de 2002 e em vigor em nosso país desde 2003.

A Convenção 169 da OIT promove o reconhecimento aos Povos Indígenas, em sentido semelhante àquele previsto na $\mathrm{CF} / 88$, que trouxe grande inovação ao reconhecer aos indígenas sua organização social, costumes, línguas, crenças e tradições, bem como os direitos originários sobre as terras que tradicionalmente ocupam, como estabelece o artigo 231. Rompeu, assim, com a percepção assimilacionista e de aculturação que até então estavam em vigor, nos moldes previstos pelo Estatuto do Índio (Lei n. 6.001/1973) e da ultrapassada Convenção 107 da OIT (WAGNER, 2020). A partir da CF/88 e da Convenção 169 da OIT, os indígenas têm direito de serem e se manterem indígenas, ou seja, seu direito à diferença está reconhecido.

Todavia, a despeito desse reconhecimento formal, observa-se que o direito à diferença ainda demanda maior empenho para que seja efetivado nas práticas e, sobretudo, em muitas decisões do Poder Judiciário, quando se toma por enfoque o acesso à justiça, como se verá.

Este estudo se vincula à vertente jurídico-sociológica, na medida em que se propõe a discutir a realização concreta de dispositivos da $\mathrm{CF} / 88$, especialmente o artigo 232 e sua relação com outras normas contidas no Estatuto do Índio, Lei 6.001/1973, e na Convenção 169 da OIT, Decreto n. 10.088/2019. Para tanto, utiliza o raciocínio indutivo, partindo de dados particulares e localizados e, a partir deles, se dirige a constatações gerais. Utiliza-se alguns julgados de maneira exemplificativa para ilustrar um movimento mais amplo, que é o acesso à justiça aos

no Estado (PINTO, 2012), por estarem ausentes do poder de influência na tomada de decisões e sem condições de participação igualitária nas esferas de deliberação política. 
indígenas. Quanto à técnica de análise de conteúdo, é pesquisa teórica, que analisa conteúdos de textos legislativos, jurisprudenciais e de obras jurídicas sobre o tema.

\section{O ACESSO À JUSTIÇA}

O acesso à justiça é tema há muito debatido entre os estudiosos do Direito, mesmo antes de ser considerado direito fundamental inserto no artigo $5^{\circ}$, XXXV e LV, da CF/88. Nesses termos, com José Afonso da Silva, ao comentar o inciso XXXV do artigo $5^{\circ}$, da CF/88, é possível afirmar que "[g]arante-se, no texto, o processo, que envolve o direito à ação, o direito de defesa, o contraditório, a isonomia processual e a bilateralidade dos atos procedimentais" (SILVA, 2009, p. 131). Assim, o princípio do acesso amplo e irrestrito à justiça tem lugar na $\mathrm{CF} / 88$ e se aplica tanto ao indivíduo quanto aos grupos coletivos e tem relação com outros direitos fundamentais igualmente assegurados.

As discussões sobre o acesso à justiça sempre buscaram desvelar os fatores que possibilitavam ou dificultavam o efetivo acesso do cidadão ao Poder Judiciário. Muito embora o conceito do acesso à justiça tenha sofrido grandes alterações com o passar do tempo, é possível afirmar que, em sua abordagem, ocupou e ocupa lugar de destaque a discussão sobre aspectos relacionados à condição socioeconômica dos demandantes.

Foi nesse sentido que Cappelletti e Garth (1988, p. 28) demonstraram os obstáculos que precisam ser transpostos para um efetivo acesso à justiça, especialmente quando se referem a litigantes individuais e a causas de pequeno valor destes em face de grandes organizações e mesmo do Estado. Tais autores identificaram também os entraves no acesso à justiça enfrentados por coletivos de pessoas com interesses ou direitos semelhantes, vinculados ou não. Assim, identificaram a necessidade de possibilitar o efetivo acesso ao Judiciário por grupos, especialmente na sociedade de massa, como é o caso dos consumidores ou em casos de dano ambiental que atingia uma coletividade.

Nesse sentido, identificaram três ondas renovatórias, que correspondem a três etapas históricas sucessivas de soluções para os problemas de acesso à justiça. Esses movimentos, a que chamaram de ondas, iniciaram mais ou menos em 1965. A primeira onda foi a de assistência judiciária aos necessitados, que visava propiciar serviços jurídicos aos pobres. A segunda onda dizia respeito às reformas tendentes a propiciar representação jurídica para os interesses difusos, principalmente no que se refere às áreas de proteção ambiental e do consumidor. Já a terceira 
onda trata do que tais autores chamaram de "enfoque de acesso à justiça", que inclui as duas ondas anteriores e vai além delas, tentando atacar as barreiras do acesso de modo mais articulado e compreensivo (CAPPELLETTI, GARTH, 1988, p. 31).

Foi na segunda onda renovatória que a tutela coletiva ganhou destaque. Conceitos tradicionais do processo civil, como é o caso da legitimidade, precisaram ser revistos, para possibilitar a presença de grupos em juízo na defesa de direitos difusos e coletivos. Pode-se dizer que isso implicou em verdadeira renovação do próprio direito processual, que então não mais lidava somente com demandantes individuais, mas também coletivos, que requeriam uma tutela jurídica igualmente coletiva.

A compreensão sobre o acesso à justiça foi ainda mais ampliada e, conforme entende Watanabe (1988), implica em acesso a uma ordem jurídica justa, que está baseada no:

\begin{abstract}
direito à informação, direito à adequação entre a ordem jurídica e a realidade socioeconômica do país, direito a uma justiça adequadamente organizada e formada por juízes inseridos na realidade social e comprometidos com o objetivo de realização da ordem jurídica justa, direito a pré-ordenação dos instrumentos processuais capazes de promover a efetiva tutela de direitos, direito à remoção de todos os obstáculos que se anteponham ao acesso e efetivo acesso à justiça com tais características. (WATANABE, 1988, p. 129)
\end{abstract}

É nessa perspectiva que se entende o acesso à justiça: o indivíduo deve poder efetivamente acionar o Poder Judiciário, independentemente de sua condição socioeconômica, mesmo que contra o próprio Estado. Deve também poder contar com assessoria jurídica adequada, quando demandar ou for demandado e não tiver condição de prover sua própria representação judicial.

Por fim, também os grupos devem poder acessar efetivamente o Judiciário, quando em jogo algum interesse coletivo, como é o caso dos Povos Indígenas, quando postulam interesse coletivo. Portanto, o acesso à justiça é direito fundamental que guarda estreita relação não só com o direito de ação, mas também com o direito de defesa, com o contraditório e a consequente paridade de armas e isonomia processual entre os atores do processo.

Coletividades hipossuficientes e minoritárias, como é o caso dos Povos Indígenas, devem poder acessar o Judiciário apesar dessa sua vulnerabilidade ou, justamente, por conta dela.

\title{
3 AS 100 REGRAS DE BRASÍlIA SOBRE ACESSO À JUSTIÇA DAS PESSOAS EM CONDIÇÃO DE VULNERABILIDADE E OS POVOS INDÍGENAS
}


As 100 Regras de Brasília sobre Acesso à Justiça das Pessoas em Condição de Vulnerabilidade foram aprovadas na XIV Conferência Judicial Ibero-americana, ocorrida em Brasília, em 2008. Tais Regras foram elaboradas no espaço de articulação das Cortes Superiores de Justiça dos países ibero-americanos, denominado Cúpula Judicial Ibero-americana, com a contribuição da Associação Ibero-americana de Ministérios Públicos (AIAMP), a Associação Interamericana de Defensorias Públicas (AIDEF), a Federação Ibero-americana de Ombudsman (FIO) e a União Ibero-americana de Colégios de Advogados (UIBA), e aprovadas por ocasião da XIV Cúpula Judicial Ibero-americana, celebrada em março de 2008, em Brasília. (RELATÓRIO GERAL DO SEMINÁRIO..., 2009, p. 5)

A Cúpula Judicial Ibero-americana “é uma organização que tem como objetivo principal adotar projetos e ações em parceria, a fim de promover o fortalecimento das instituições judiciárias e, por extensão, da democracia na Comunidade Ibero-Americana de Nações. " (CÚPULA JUDICIAL IBERO-AMERICANA..., s.d.). A Cúpula reúne presidentes de cortes supremas, tribunais superiores e de conselhos da magistratura ou órgãos equivalentes de 23 países. São eles: Andorra, Argentina, Bolívia, Brasil, Colômbia, Costa Rica, Cuba, Chile, República Dominicana, Equador, El Salvador, Espanha, Guatemala, Honduras, México, Nicarágua, Panamá, Paraguai, Peru, Portugal, Porto Rico, Uruguai e Venezuela (CÚPULA JUDICIAL IBERO-AMERICANA..., s.d.).

As 100 Regras de Brasília sobre Acesso à Justiça das Pessoas em Condição de Vulnerabilidade alinha diretrizes que têm como escopo fomentar política judicial que atenda às especificidades de grupos vulneráveis, de acordo com a normativa internacional dos direitos humanos, respeitadas as diferenças no marco da igualdade. (RELATÓRIO GERAL DO SEMINÁRIO..., 2009, p. 5)

Nelas foram desenvolvidos os princípios reunidos na "Carta de Direitos das Pessoas perante a Justiça no Espaço Judicial Ibero-americano" (Cancún 2002), especificamente os que se incluem na parte intitulada "Uma justiça que protege os mais débeis" (seção 23 a 34). Logo na exposição de motivos das regras fica delimitado que:

O sistema judicial deve configurar-se, e está a configurar-se, como um instrumento para a defesa efetiva dos direitos das pessoas em condição de vulnerabilidade. Pouca utilidade tem que o Estado reconheça formalmente um direito se o seu titular não pode aceder de forma efetiva ao sistema de justiça para obter a tutela do dito direito. Se bem que a dificuldade de garantir a eficácia dos direitos afeta com caráter geral todos os âmbitos da política pública, é ainda maior quando se trata de pessoas em condição de vulnerabilidade dado que estas encontram obstáculos maiores para o seu exercício. Por isso, dever-se-á levar a cabo uma atuação mais intensa para vencer, eliminar ou 
mitigar as ditas limitações. Desta forma, o próprio sistema de justiça pode contribuir de forma importante para a redução das desigualdades sociais, favorecendo a coesão social. (REGRAS DE ACESSO À JUSTIÇA DAS..., 2008, p. 4)

Em suas regras terceira e quarta, o documento conceitua o que considera pessoas em condição de vulnerabilidade. Nesse sentido, estabelece que:

(3) Consideram-se em condição de vulnerabilidade aquelas pessoas que, por razão da sua idade, gênero, estado físico ou mental, ou por circunstâncias sociais, econômicas, étnicas e/ou culturais, encontram especiais dificuldades em exercitar com plenitude perante o sistema de justiça os direitos reconhecidos pelo ordenamento jurídico.

(4) Poderão constituir causas de vulnerabilidade, entre outras, as seguintes: a idade, a incapacidade, a pertença a comunidades indígenas ou a minorias, a vitimização, a migração e o deslocamento interno, a pobreza, o gênero e a privação de liberdade. A concreta determinação das pessoas em condição de vulnerabilidade em cada país dependerá das suas características específicas, ou inclusive do seu nível de desenvolvimento social e econômico. (REGRAS DE ACESSO À JUSTIÇA DAS..., 2008, p. 5-6)

O documento reconhece que o fato de pertencer a uma comunidade indígena pode constituir causa de vulnerabilidade. Ao observar a realidade brasileira, é possível afirmar a vulnerabilidade dos Povos Indígenas.

Muito embora tenham circunstâncias que os distinguem significativamente uns dos outros a depender da forma como vivem e da região em que vivem, de maneira geral, verificase que a vulnerabilidade é traço característico a todos os Povos Indígenas no Brasil. Isso se aplica ainda hoje: seja por diferenças linguísticas ou culturais, seja por ausência de informação adequada, seja por hipossuficiência econômica, seja por fragilidade de aspectos envolvendo a saúde ou por dificuldades em compreender as formas de organização da sociedade envolvente, ou mesmo por todos esses fatores concomitantemente ou ainda por outros fatores. De maneira geral, basta observar o tratamento jurídico que lhes foi dispensado ao longo da história brasileira para verificar que continuam sendo pessoas e grupos em situação de vulnerabilidade.

Dentre as 100 Regras de Brasília sobre Acesso à Justiça das Pessoas em Condição de Vulnerabilidade, a regra de n. 79 estabelece diretriz importante para os Estados no que se refere ao trato judicial com as populações indígenas. Nessa direção, orienta que "na celebração dos atos judiciais respeitar-se-á a dignidade, os costumes e as tradições culturais das pessoas integrantes de comunidades indígenas, conforme a legislação interna de cada país.” (REGRAS DE ACESSO À JUSTIÇA DAS..., 2008, p. 19)

As 100 Regras de Brasília foram atualizadas em abril de 2018, durante a XIX Cúpula Judicial Ibero-americana, ocorrida em Quito, Equador. A atualização se deu em 73 das 100 
regras e teve por objetivo adequá-las aos avanços da regulamentação internacional, aos novos conceitos e ações no campo do acesso à justiça (REGLAS DE BRASILIA SOBRE ..., 2018).

Conforme consta em sua versão atualizada, a regra de n. 79 passou a ter a seguinte redação: "Na celebração dos atos judiciais respeitar-se-á a dignidade e a cosmovisão, os costumes e as tradições culturais das pessoas integrantes de povos e comunidades indígenas, pessoas afrodescendentes e outras diversidades étnicas e culturais, conforme o ordenamento jurídico de cada país." (REGLAS DE BRASILIA SOBRE ..., 2018, p. 18) (tradução nossa) ${ }^{3}$

Para além da regra 79, várias outras também aplicam-se aos Povos Indígenas e são manifestação do reconhecimento do direito à diferença. Pelo menos do ponto de vista formal, a legislação brasileira segue em direção próxima àquela apontada por tais regras. A CF/88 consagrou o direito à diferença, a diversidade cultural e étnica aos Povos Indígenas em vários dispositivos, para além dos artigos 231 e 232. Corolário disso, se reconhece o Brasil como Estado pluriétnico, que não se esgota nas diferentes etnias, como evidencia o parágrafo $1^{\circ}$ do artigo 215 da CF/88 (PEREIRA, s/d., p. 2). A CF/88 impôs um novo padrão de respeito à heterogeneidade dos grupos que compõe a nação brasileira.

Corrobora tal entendimento o disposto na Convenção 169 da OIT. É possível afirmar que a Convenção auxilia na compreensão do que seja um estado pluriétnico, pois ela indica características para identificar grupos que integram um estado nacional. Embora a Convenção refira-se a grupos indígenas e tribais, a ideia envolvida implica no reconhecimento de diversidade, de alteridade, de não uniformidade e tal compreensão aplica-se ao estado pluriétnico também (WAGNER, 2014). Nesse sentido, três são os critérios fundamentais apontados pela Convenção para determinar os grupos tribais e indígenas, aos quais ela se aplica:

\begin{abstract}
A existência de condições sociais, culturais e econômicas diferentes de outros setores da sociedade nacional; a presença de uma organização social regida total ou parcialmente por regras e tradições próprias, e a auto-identificação, entendida como a consciência que tem o grupo social de sua identidade tribal. Este último critério é fundamental na identificação e reconhecimento dos grupos tribais que fazem parte de um país (OIT, 2011).
\end{abstract}

A partir dessas características, verifica-se que tal Convenção vai ao encontro do disposto na CF/88, art. 231. Além disso, observa-se ainda que as 100 Regras de Brasília dialogam com

\footnotetext{
${ }^{3}$ Do original: "En la celebración de los actos judiciales se respetará la dignidad y cosmovisión, las costumbres y las tradiciones culturales de las personas pertenecientes a pueblos y comunidades indígenas, personas afrodescendientes y otras diversidades étnicas y culturales conforme al ordenamiento jurídico de cada país." "ILEP:(REGLAS DE BRASILIA SOBRE ..., 2018, p. 18)
} 
essa compreensão, na medida em que estabelecem a necessidade de que o Poder Judiciário atue reconhecendo e respeitando a diversidade dos Povos Indígenas através de diferentes ações, que vão desde a adequação da linguagem até o respeito às práticas indígenas de resolução de conflitos.

A tutela jurídica de interesses coletivos, já prevista em leis especiais, como é o caso da Lei da Ação Civil Pública (LACP), Lei n. 7.347/85, em muito se ampliou a partir da CF/88. Para os indígenas, isso se deu de maneira mais ampla no plano legal, como já afirmado, a partir do art. $232, \mathrm{CF} / 88$.

As 100 Regras de Brasília, em sua versão atualizada em 2018, representam um importante passo. São orientações para a atuação do Poder Judiciário de todos os países que integram a Cúpula Judicial Ibero-americana, no sentido de tomar ações concretas para superar as barreiras de acesso à justiça aos vulneráveis.

\section{POVOS INDÍGENAS E O ESTADO BRASILEIRO: UMA “RELAÇÃO” DIFÍCIL}

Para tratar do acesso à justiça dos Povos Indígenas, necessário antes fazer breve incursão histórica no tratamento jurídico que receberam do Estado brasileiro através da legislação. A tutela foi instituto jurídico utilizado pelo Estado para se relacionar com os indígenas, supostamente como instrumento de proteção individual que, muitas vezes, serviu muito mais para subjugá-los ou limitá-los em seu exercício de direitos do que para protegê-los.

Souza Filho (1998, p. 93) debruçou-se sobre tal instituto, extraído do direito privado, para ser utilizado como instrumento de proteção aos indígenas. Demonstrou em sua obra que a tutela estatal, também chamada de orfanológica, teve origem em Lei de 27 de outubro de 1831, que revogou as cartas régias de 1808, que declaravam guerra aos índios de São Paulo e Minas Gerais e autorizava a escravidão dos índios aprisionados durante quinze anos. Para tais índios saídos do cárcere foi estabelecida a tutela: eles seriam socorridos pelo Tesouro do Estado até que os juízes de órfãos lhes encontrassem trabalho, através do qual pudessem sobreviver (SOUZA FILHO, 1998, p. 93). Aí já é possível identificar a presença do ideal assimilacionista, segundo o qual os índios deixariam de ser índios e se integrariam à comunidade nacional de forma harmônica a partir do exercício do trabalho.

Com um Decreto em 03 de junho de 1833, os juízes de órfãos ficaram encarregados da administração dos bens dos índios, em substituição aos extintos Ouvidores das Comarcas. Isso 
foi confirmado pelo Regulamento n. 143, de 25 de março de 1842. Essa administração dos bens dos índios, prevista tanto no Decreto de 1833 quanto no Regulamento de 1842, aplicou-se a todos os índios, não só aos saídos do cativeiro em razão do término das chamadas guerras santas. A partir daí, todos os índios eram tutelados pelo Estado através dos juízes de órfãos e não tinham a disponibilidade de seus bens.

Se por um lado é possível afirmar, ainda com Souza Filho (1998), que todas essas normas tinham caráter protecionista, por outro é possível perceber que paralelamente a isso, acabaram por ressaltar o tratamento restritivo da capacidade dos indígenas. Assim, por serem diferentes dos não índios, foram tidos como limitados e incapazes de se autodeterminar. Foram considerados primitivos, como se estivessem em estágio inicial num percurso inevitável rumo à civilização ocidental e seus valores.

Com a entrada em vigor do Código Civil de 1916 (CC/16), aos índios passou a ser conferida incapacidade relativa, nos termos do artigo $6^{\circ}$, assim:

\footnotetext{
Art. $6^{\circ}$ São incapazes, relativamente a certos atos, ou à maneira de os exercer:

$[\ldots]$

III - os silvícolas

Parágrafo Único. Os silvícolas ficarão sujeitos ao regime tutelar, estabelecido em leis e regulamentos especiais, o qual cessará à medida que se forem adaptando à civilização do País. (BRASIL, 1916)
}

Interessante notar que o regime tutelar demandava lei ou regulamento especial que o regrasse. Portanto, na prática, a incapacidade relativa dos indígenas não tinha como ser efetivada, na medida em que dependia de lei ou regulamento especial. É nesse sentido que vai a pertinente advertência e análise de Berno (2007, p. 41):

[...] a tutela dos índios prevista estava em flagrante contradição jurídica na medida em que se trata de instrumento de proteção individual em função de uma situação excepcional de incapacidade. Assim, não poderia ser aplicada a toda uma coletividade de indivíduos como regra geral e os artigos 406 a 485 do Código Civil de 1916, que se referem à tutela de incapazes, não seriam aplicáveis aos índios sob o aspecto sistêmico, ou seja, dependeria de regulamentação por leis especiais. A incapacidade relativa do índio não podia ser considerada auto-aplicável. (BERNO, 2007, p. 41)

Em 1967 foi criada a Fundação Nacional do Índio (FUNAI), em substituição ao SPI, que seguiu seu papel de "representante" dos Povos Indígenas e ficou responsável por sua tutela. Essa tutela exercida pela FUNAI, que seguiu os moldes anteriores à criação dessa fundação, era a tutela do direito civil, mas com peculiaridades que afrontavam o regramento geral desse instituto jurídico previsto no Código Civil. 
Como demonstrou Souza Filho (1998), a tutela aos índios era exercida pela FUNAI de forma coletiva. Esta não era obrigada a prestar contas de seu múnus. Além disso, quando em conflito os interesses dos tutelados com os do órgão tutor, prevalecia o entendimento deste, já que os tutelados, por suas características peculiares, em regra não tinham meios de questionar efetivamente o exercício irregular da tutela pela FUNAI. Por fim, chama atenção que tal tutela era exercida independentemente de prestação de caução e não era efetivamente fiscalizada. $\mathrm{Ou}$ seja, a tutela aplicada aos indígenas era peculiar e não seguia sequer o regramento básico previsto para a tutela do direito civil, que tem por escopo proteger os direitos, interesses e patrimônio do tutelado (SOUZA FILHO, 1998).

Em 1973 entrou em vigor o Estatuto do Índio, Lei 6.001, que seguiu determinando a aplicação da tutela do direito civil aos índios, a ser exercida pelo órgão indigenista oficial brasileiro: a FUNAI. O Estatuto do Índio, calcado no ideal integracionista, em seu artigo $4^{\circ}$ diferenciava os indígenas em três categorias: os índios isolados, os índios em vias de integração e os índios integrados. Essas três categorias seriam como que uma escala sucessiva cujo objetivo final era a integração do índio à sociedade nacional, como se fossem deixar de ser indígenas para se tornarem brasileiros. Tanto é assim que em seu art. $1^{\circ}$, estabelece que:

Art. $1^{\circ}$ Esta Lei regula a situação jurídica dos índios ou silvícolas e das comunidades indígenas, com o propósito de preservar a sua cultura e integrá-los, progressiva e harmoniosamente, à comunhão nacional (BRASIL, 1973, grifo nosso).

Segundo dispôs o Estatuto do Índio, a tutela ou assistência seria prestada apenas aos indígenas isolados. Os integrados já não gozariam dessa "proteção" estatal, não recebendo nenhuma discriminação positiva em razão de sua peculiar condição de indígenas. Ao ser aplicado o direito civil, no que tange à capacidade, os índios foram tratados individualmente, não sendo considerados seus direitos coletivos. Vale lembrar que o Código Civil de 1916 era iluminado pelo individualismo e patrimonialismo, ou seja, seus valores fundantes eram muito diversos daqueles que regiam a grande maioria das comunidades indígenas no país.

Foi somente a partir da $\mathrm{CF} / 88$ que o tratamento jurídico aos indígenas sofreu grande modificação. Essa foi a primeira constituição brasileira que destinou um capítulo próprio dedicado aos Povos Indígenas e seus direitos. Ela superou a teoria assimilacionista e estabeleceu o direito à diferença e à autodeterminação desses povos. Embora ainda não revogado, o Estatuto do Índio em grande parte não pode mais ser aplicado, por afrontar diretamente o disposto na $\mathrm{CF} / 88$. 
O Código Civil de 2002 (CC/02) não trata mais da capacidade civil dos indígenas, estabelecendo no parágrafo único do artigo $4^{\circ}$ que a capacidade dos indígenas será regulada por legislação especial. Assim, encerrada a tutela nos moldes até então aplicados.

A discussão da tutela aos indígenas tem relação direta com sua legitimidade processual. A CF/88, art. 232, estabelece que os índios, suas comunidades e organizações são partes legítimas para ingressarem em juízo em defesa de seus direitos e interesses, intervindo o MP em todos os atos do processo. O disposto neste artigo colaborou para a compreensão da derrogação da tutela aos indígenas, como a doutrina especializada passou a argumentar a partir da $\mathrm{CF} / 88$, dada a incompatibilidade da convivência, a um só tempo, do tratamento tutelar previsto no Estatuto do Índio, com a legitimidade processual prevista nos moldes do art. $232 \mathrm{da}$ CF/88. Nessa direção, entre outros, Souza Filho (1998), Oliveira (2008), Lima; BarrosoHoffmann (2002).

\section{POVOS INDÍGENAS E PROCESSO}

São legitimados ao processo, nos ensinamentos de Fazzalari (2006, p. 379), “aqueles que se assumem titulares do direito e vítimas da lesão; aqueles que são indicados como titulares da obrigação e autores da lesão.” Nesse sentido, e ainda a partir desse autor, é possível afirmar que a situação legitimante, que estabelece a legitimação para participar de um processo, é aquela com base na qual se determina quem pode estar em juízo para dizer e contradizer: autores, réus etc.

Nessa perspectiva, então, quem é legitimado para postular em juízo por seus direitos e interesses são os próprios indígenas, coletiva ou individualmente. Assim, a legitimação da FUNAI e do Ministério Público Federal (MPF) é extraordinária, na medida em que são sujeitos diferentes dos destinatários da tutela, e, portanto, decorre de lei.

A legitimidade processual dos indígenas foi prevista inicialmente pelo Estatuto do Índio, no artigo 37, que estabelecia que "os grupos tribais ou comunidades indígenas são partes legítimas para a defesa dos seus direitos em juízo, cabendo-lhes, no caso, a assistência do Ministério Público Federal ou do órgão de proteção ao índio” (BRASIL, 1973).

Por conta dessa previsão legal, Dallari (1991, p. 317) afirmou que o Estatuto do Índio foi um avanço em termos de reconhecimento e proteção dos direitos dos indígenas e dos grupos 
indígenas. O autor reconheceu no Estatuto do Índio a inovação por estabelecer legitimidade processual às comunidades indígenas, desde que com a assistência do MPF ou da FUNAI.

Todavia, os órgãos incumbidos da tutela dos índios foram incapazes de realizar tal tutela de forma adequada e atendendo aos interesses dos indígenas. Muitas vezes tais órgãos foram omissos e deficientes em seu múnus público, como denunciado pelos próprios indígenas e por entidades defensoras dos direitos indígenas (DALLARI, 1991).

Portanto, aquela legitimidade prevista no artigo 37 do Estatuto do Índio efetivamente não representou o grande avanço apontado por Dallari (1991), já que, em grande medida, o órgão oficial responsável pela política indigenista nacional, pela tutela e pela assistência aos indígenas em processos judiciais falhou. Exemplos disso são abundantes tanto no Relatório Figueiredo quanto no Relatório da Comissão Nacional da Verdade, que denunciaram uma infinidade de arbitrariedades cometidas contra os indígenas.

Dessa maneira, é possível afirmar que a grande inovação do artigo 232 da CF/88 foi o fato de possibilitar a legitimidade processual dos indígenas e das comunidades indígenas independentemente da assistência do MP ou da FUNAI. Portanto, a partir de 1988, a possibilidade de atuação dos indígenas perante o Judiciário se ampliou significativamente, podendo inclusive demandar contra a própria FUNAI, órgão federal incumbido até então de sua tutela. Nesse sentido, a previsão do art. 232, CF/88, implicou em ampliação do acesso à justiça dessa parcela minoritária e hipossuficiente da população.

O acesso à justiça dos grupos indígenas, então, está previsto desde o Estatuto do Índio, considerado apenas em seu aspecto ativo, ou seja, de ingressar com ações perante o Judiciário, independentemente de representação. Todavia, tal previsão legal não foi suficiente para assegurar o imediato e efetivo acesso dos indígenas ao Judiciário sem a assistência da FUNAI ou do MPF. Nesse sentido, citamos, a título meramente exemplificativo, três decisões judiciais que, muito embora posteriores à $\mathrm{CF} / 88$, demonstram que a legitimidade processual dos indígenas assegurada no art. 232, CF/88, não teve reconhecimento e aplicação imediatos.

PROCESSUAL CIVIL. AÇÃO PROPOSTA POR INDÍGENA. INDEFERIMENTO DE PLANO DA INICIAL, POR INCAPACIDADE PROCESSUAL DA AUTORA. DESCABIMENTO. I - O Juízo a quo, verificando a incapacidade processual da autora, em vista de sua condição de indígena, houve por bem indeferir de plano a inicial, com fundamento no art. 267, IV, sem oferecer oportunidade para sanar o defeito, o que não se admite, diante dos expressos termos do artigo 284, CPC. II Além disso, o art. 232, parte final, CF, prevê expressamente a obrigatoriedade de intervenção do Ministério Público em todos os atos de processo envolvendo indígenas, procedimento não obedecido pelo magistrado sentenciante. III - Apelação provida para anular a sentença e determinar o retorno do autos à origem, para regular 
prosseguimento, com a intervenção do Ministério Público Federal no feito. (BRASIL, 2005a).

PREVIDENCIÁRIO - SALÁRIO-MATERNIDADE - ART. 71 DA LEI No 8213/91 - INDÍGENA - EXTINÇÃO DO FEITO, SEM JULGAMENTO DO MÉRITO SENTENÇA ANULADA. 1. A Constituição Federal em seu artigo 232 assegura ao índio o acesso à Justiça. A autora revela consciência e conhecimento de seus atos, pois possui cédula de identidade e CTPS, ambas com assinatura aposta pela autora, demonstrando, assim, capacidade para ingressar em juízo. 2. Demonstrada a capacidade processual da autora deve o processo ter seu regular prosseguimento, inclusive, mediante intervenção do Ministério Público de todos os atos praticados no feito, a teor do que dispõe o citado dispositivo constitucional. 3. Apelação provida para o fim de anular a sentença, determinando a remessa do processo à vara de origem para regular prosseguimento do feito." (BRASIL, 2006).

PREVIDENCIÁRIO. SALÁRIO-MATERNIDADE. AÇÃO PROPOSTA POR INDÍGENA. INDEFERIMENTO DE INICIAL POR INCAPACIDADE PROCESSUAL DA AUTORA. AUSÊNCIA DE INTERVENÇÃO DO MINISTÉRIO PÚBLICO. I - A sentença é nula, considerando que não houve, em primeiro grau, manifestação do Ministério Público, em nenhum dos atos do processo, contrariando expressa previsão Constitucional (art. 232). II - Não há que se falar em ausência de capacidade para estar em juízo, à vista de que o parágrafo único, do art. $8^{\circ}$, da Lei ${ }^{\circ}$ 6.001/73 (Estatuto do Índio), prevê que as regras do caput não se aplicam quando o indígena revela consciência e conhecimento do ato praticado e este não lhe é prejudicial. III - Requerente trouxe aos autos documentos que demonstram que tem consciência plena de seus atos e pleiteia benefício (salário-maternidade) que não lhe pode ser prejudicial. IV - Necessidade de reconhecimento da capacidade postulatória da apelante. V - Recurso da autora provido para julgar anular a sentença e determinar o retorno dos autos à origem, para regular prosseguimento do feito, com a intervenção do Ministério Público.” (BRASIL, 2005b).

Essas decisões são exemplificativas de que a legitimidade processual dos indígenas foi questionada, em desacordo com o previsto no art. $232 \mathrm{da} \mathrm{CF} / 88$. Interessante notar que as decisões de primeiro grau que negaram a legitimidade processual às indígenas para demandarem o INSS sem a representação da FUNAI ou do MPF foram reformadas, admitindo que as autoras demonstraram atender aos requisitos para serem consideradas integradas, nos termos do art. $7^{\circ}$ do Estatuto do Índio.

Até mesmo esse fundamento, da integração das indígenas por possuírem documentos de identificação pessoal etc., está equivocado à luz do disposto no art. 232, CF/88. Ora, se o Estatuto do Índio foi derrogado em parte e superado está o paradigma integracionista, não cabe mais utilizar tal classificação de índios em integrados, em vias de integração e isolados. É distinção que a CF/88 não mais adota, na medida em que reconhece a legitimidade processual de todo e qualquer indígena para estar em juízo.

Interessante notar ainda que todas as decisões colacionadas referem o art. 232, CF/88, mas apenas para lembrar da necessária participação do MPF como fiscal da lei no feito. A 
legitimidade das autoras, indígenas, decorre diretamente do art. 232, CF/88 e, assim, não está adstrita à participação da FUNAI ou do MPF. Por sua vez, a este cabe atuar como fiscal da lei em todas as ações que envolvam direitos indígenas em razão do disposto não só no art. 232, mas também no art. $129, \mathrm{~V}, \mathrm{CF} / 88$.

Portanto, muito embora tenham sido acertadas as decisões em grau de recurso, ao reconhecerem a legitimidade processual das autoras indígenas, seu fundamento foi equivocado. Sua legitimidade decorre diretamente do art. 232, CF/88 e não da demonstração de que são integradas, conforme previa o Estatuto do Índio.

Tal classificação estava prevista no artigo $4^{\circ}$ do Estatuto do Índio e já não pode mais ser aplicado, posto derrogado pelo artigo 231 da $\mathrm{CF} / 88$, ao reconhecer aos indígenas o direito à diferença. Ou seja, o conteúdo do artigo $4^{\circ}$ do Estatuto do Índio é incompatível com a ordem constitucional estabelecida pela $\mathrm{CF} / 88$ e, além disso, também contraria o disposto na Convenção 169 da OIT. O paradigma assimilacionista e de integração dos indígenas, com o qual o artigo $4^{\circ}$. estava alinhado, foi superado e, portanto, também superado está o artigo $4^{\circ}$ do Estatuto do Índio.

Confrontando outras decisões judiciais, verifica-se que há a admissão da legitimidade das comunidades indígenas, inclusive com referência expressa ao art. 232, CF/88 e à legitimidade processual dos indígenas e das comunidades indígenas, mesmo que de forma indireta, como é o caso da Apelação Cível n. 1997.01.00.010062-9/TO, TRF 1ª Região, julgada em12/03/2007, Relator João Batista Moreira:

PROCESSUAL CIVIL E CIVIL. AÇÃO CIVIL PÚBLICA. TERRAS INDÍGENAS. CONSTRUÇÃO DE OBRAS PÚBLICAS PELO GOVERNO DO ESTADO DO TOCANTINS. LEGITIMIDADE ATIVA DO MPF. ASSISTÊNCIA DA FUNAI. INOBSERVÂNCIA DO ART. 20 DA LEI 6.001/73. PARALISAÇÃO DAS OBRAS. DESFAZIMENTO DAS PARTES JÁ EXECUTADAS. RAZOABILIDADE AUSENTE. PUBLICAÇÃO DA SENTENÇA EM JORNAIS DE GRANDE CIRCUlAÇÃO. AUSÊNCIA DE PREVISÃ O LEGAL. 1. O Ministério Público Federal ostenta legitimidade para ajuizar ação civil pública que visa à tutela do meio ambiente (interesse difuso) e de interesses de comunidades indígenas (art. 129, III e V, CF/88; art. 6", VII, "b" e "c", LC 75/93). 2. Embora os índios, suas comunidades e organizações tenham legitimidade para ingressar em juízo na defesa de seus direitos e interesses (art. 232, CF/88), isso não impede a FUNAI de adotar medidas com o mesmo objetivo (art. 231, CF/88; art. 35, Lei 6.001/73). 3 . A realização de obras públicas em terras indígenas (excetuada a mera conservação das já existentes) pressupõe, entre outras, a adoção das seguintes providências: decreto do Presidente da República determinando a intervenção em área indígena para a realização de obra que interesse ao desenvolvimento nacional; utilização preferencial de meios suasórios para viabilizar a realização da obra; destinação à comunidade indígena removida (entenda-se: privada total ou parcialmente de suas terras em razão da obra) de área equivalente à perdida, inclusive quanto às condições ecológicas; ressarcimento de todos os prejuízos suportados pela comunidade indígena; assistência direta da FUNAI (art. 231, §6, $\mathrm{CF} / 88$, art. 20, L. 6.001/73). 4. Afigura-se ilegítima a 
realização de obras públicas (construção de ponte e pavimentação asfáltica de rodovias estaduais) pelo Estado do Tocantins em terras indígenas sem que haja prévio decreto presidencial, destinação de áreas equivalentes às perdidas às comunidades indígenas afetadas, ressarcimento de todos os prejuízos suportados por essas comunidades e assistência direta da FUNAI. 5. [...] (BRASIL, 2007, grifo nosso).

No mesmo sentido, segue outra decisão da $3^{\mathrm{a}}$ Turma do TRF da $1^{\mathrm{a}}$ Região, no Agravo de Instrumento n. 2008.01.00.006925-2/BA, julgado em 13/04/2009, cujo relator foi Cândido Ribeiro:

PROCESSUAL CIVIL E CIVIL. AGRAVO DE INSTRUMENTO. AÇÃO CIVIL PÚBLICA. SERVIDÃO DE PASSAGEM EM TERRAS INDÍGENAS PARA FINS DE FORNECIMENTO DE ENERGIA ELÉTRICA. INTERESSE RECURSAL DA FUNAI. ACESSO À RESERVA PARA A MANUTENÇÃO DA REDE ELÉTRICA. AUTORIZAÇÃO FORMAL E PRÉVIA DA FUNAI. EXIGÊNCIA QUE NÃO SE MOSTRA RAZOÁVEL. ABSTENÇÃO DE COBRANÇA PELA UTILIZAÇÃO DA ENEGIA ELÉTRICA. I. O fato de os índios, suas comunidades e organizações terem legitimidade para ingressar em juízo na defesa de seus direitos e interesses (art. 232 da CF) não impede a FUNAI de adotar medidas com o mesmo objetivo. Afinal, compete à União proteger e fazer respeitar todos os bens indígenas (art. 231 da CF), o que é feito através da FUNAI, a quem cabe "a defesa judicial [...] dos direitos dos silvícolas e das comunidades indígenas" (art. 35 da Lei n. 6.001/73). II. [...] (BRASIL, 2009, grifo nosso).

Essas decisões são meramente exemplificativas, mas a partir delas é possível demonstrar a atuação das comunidades indígenas perante o Judiciário na defesa de seus direitos e interesses, independentemente da assistência da FUNAI ou do MPF. Nesse sentido, é possível encontrar vários julgados que atestam isso, inclusive perante o Supremo Tribunal Federal (STF) e o Superior Tribunal de Justiça (STJ).

Cita-se a demarcação da Terra Indígena Raposa Serra do Sol, em Roraima, julgada pelo STF em 2009, através da Petição n. 3388. Nessa demanda estão presentes várias comunidades indígenas para postular diretamente por seus interesses quanto àquele território (BRASIL, 2009). Além disso, é possível encontrar um crescente número de demandas nas quais as comunidades indígenas atuaram na condição de assistentes, como é o caso da Ação Cível Originária 312/BA, julgada pelo STF em no ano de 2012, na qual a comunidade indígena Pataxó Hã Hã Hã foi admitida como assistente simples da autora, a União (BRASIL, 2012).

Atualmente, merecem destaque, por sua temática e atualidade, a Arguição de Descumprimento de Preceito Fundamental (ADPF) n. 709 e o Recurso Extraordinário (RE) n. 1.017.365, em trâmite perante o STF. Em ambas as demandas, participam várias comunidades 
indígenas e também suas organizações ${ }^{4}$. A partir desses julgados, é possível inferir que a participação de comunidades indígenas e também de indígenas individualmente, em processos judiciais, têm aumentado significativamente, em reconhecimento à legitimidade processual assegurada pelo art. 232, CF/88.

Todavia, importante ressaltar que esse significativo avanço não implicou em impedimento à FUNAI e ao MPF para que atuem na defesa dos interesses individuais e coletivos dos indígenas. É assim, pois à União compete respeitar e fazer respeitar os direitos indígenas, conforme prevê o art. 231, CF/88. Ela o faz através da FUNAI, conforme estabelece $\mathrm{o}$ art. 35 do Estatuto do Índio. Além disso, o MPF também deve atuar na defesa e proteção dos direitos indígenas em decorrência do art. 129, III e V, CF/88 e também em razão do disposto no art. 6", VII, "b" e "cc", da LC 75/93.

Portanto, na defesa dos direitos e interesses indígenas podem agir como legitimados diretos tanto os indígenas individualmente, quanto suas comunidades ou entidades e seguem sendo legitimados extraordinários a FUNAI e o MPF. Esse entendimento está alinhado com a situação peculiar de vulnerabilidade na qual os indígenas se encontram.

Especificamente no que se refere à ação civil pública prevista na Lei n. 7.347/85, entende-se que as comunidades e organizações indígenas, independentemente de atenderem aos requisitos de pré-constituição previstos no art. $5^{\circ}, \mathrm{V}$, da lei, têm legitimidade para propor tal ação na defesa de seus direitos e interesses coletivos. Esse entendimento decorre do disposto no parágrafo $4^{\circ}$ mesmo artigo, que afirma que "o requisito da pré-constituição poderá ser dispensado pelo juiz, quando haja manifesto interesse social evidenciado pela dimensão ou característica do dano, ou pela relevância do bem jurídico a ser protegido" (BRASIL, 1985).

O parágrafo $4^{\circ}$ do artigo $5^{\circ}$ da LACP se aplica aos Povos Indígenas, quando exercem seu direito de ação, nos termos do art. 232, CF/88. Todavia, mesmo que inexistisse tal permissivo na LACP, as organizações e sociedades indígenas seguem sendo legitimadas a ingressar com ação civil pública na defesa de seus direitos e interesses coletivos em razão do

\footnotetext{
${ }^{4} \mathrm{Na}$ ADPF 709, uma das requerentes é a Articulação dos Povos Indígenas do Brasil (APIB), organização indígena que demanda ações efetivas do governo federal no combate à pandemia de Covid 19 nas aldeias indígenas. Além dela, várias outras organizações indígenas participam na condição de Amicus Curiae. No RE n. 1.017.365 é discutida a posse tradicional de área por indígenas no estado de Santa Catarina. Nele foi reconhecida a repercussão geral da questão constitucional envolvida: "É dotada de repercussão geral a questão constitucional referente à definição do estatuto jurídico-constitucional das relações de posse das áreas de tradicional ocupação indígena à luz das regras dispostas no artigo 231 do texto constitucional." Nesta demanda, a Comunidade Indígena Xokleng da Terra Indígena Ibiramala Klaño é parte e há várias organizações indígenas que figuram como Amicus Curiae (BRASIL, 2020).
} 
art. 232 da CF/88 e, principalmente, em virtude do reconhecimento que o Estado brasileiro assegurou a sua cultura e diversidade, conforme art. 231, CF/88.

$\mathrm{O}$ reconhecimento ao direito à diferença, a autodeterminação e a possibilidade de ser parte em processo judicial, independentemente de assistência, não se conciliam com uma exigência de cunho formal que se aplica para a sociedade envolvente, não indígena. Do contrário, haverá contradição e desrespeito ao previsto no art. 231 da CF/88.

Os indígenas devem poder se relacionar com os não índios e participar do que atenda a seus interesses e prioridades na sociedade envolvente apenas a partir de suas estruturas comunitárias próprias, sem necessidade de constituir pessoa jurídica. Entendemos que deveriam poder estabelecer relações, inclusive de ordem jurídica, entre si e com a sociedade envolvente, sem necessitar adotar modelos do direito dos não índios. Para tanto, sempre que necessário, deveriam poder contar com a participação da FUNAI, que segue sendo o órgão estatal incumbido de zelar pelos direitos e interesses dos Povos Indígenas.

Essa seria forma de assegurar um efetivo acesso à ordem jurídica justa, na perspectiva de Watanabi (1988), e em conformidade com a situação peculiar de vulnerabilidade que cada povo indígena pode apresentar.

\title{
6 CONSIDERAÇÕES FINAIS
}

\begin{abstract}
O homem é o único ser vivo a poder "virar a ampulheta", só ele está em posição de se subtrair ao fluir irreversível do tempo físico ligando aquilo que, a cada instante, ameaça desligar-se. Com o homem surge com efeito a possibilidade de uma repetição reflexiva do passado e de uma construção antecipativa do futuro - a capacidade de reinterpretar o passado (não fazer com que ele nunca tenha existido, mas imprimir-lhe um outro sentido, tirar partido dos seus ensinamentos, por exemplo, ou ainda assumir a responsabilidade pelos seus erros) e a faculdade de orientar o futuro (não fazer com que ele não ocorra, mas imprimir um sentido - significado e direção - àquilo que acontecer). (OST, 1999, p. 30)
\end{abstract}

O acesso à justiça, de maneira geral, segue sendo direito fundamental que carece de efetividade, apesar de todos os inúmeros esforços que têm sido envidados por diferentes órgãos e atores sociais, a exemplo das 100 Regras de Brasília. No que se refere aos vulneráveis, como é o caso dos Povos Indígenas, tal acesso permanece ainda como verdadeiro desafio. Esse desafio em nosso país ganhou novos ares e fôlego para ser enfrentado, especialmente a partir da CF/88.

$\mathrm{O}$ acesso à justiça pode ser analisado sob diferentes perspectivas, mas no que se refere aos Povos Indígenas, o estudo mais relevante precisa enfrentar o acesso à justiça coletivo, já que parte significativa dos direitos e interesses dos indígenas dizem respeito ao seu grupo, ao 
seu povo, como é o caso do direito às terras que tradicionalmente ocupam, a sua peculiaridade cultural e sua autodeterminação.

Além disso, é preciso pensar o acesso independentemente de questões de ordem formal, como é o caso da pré-constituição para que possam ingressar com ação civil pública, por exemplo. Considerando que aos indígenas é reconhecida sua organização social, costumes, línguas crenças e tradições, nos termos do art. 231 da CF/88, faz-se necessário enfrentar velhos problemas sob novos enfoques, ou seja, não é possível assegurar o acesso à justiça nos moldes aplicados aos não índios a essa parcela minoritária e vulnerável da população. Além disso, é necessário reconhecer que a vulnerabilidade não se traduz em falta de legitimidade processual. Pelo contrário: é preciso que o processo e o Poder Judiciário como um todo se ajustem de maneira a contemplar a diversidade inerente a sociedade brasileira, tal como indicam as 100 Regras de Brasília.

Assim, romper com o passado e investir no futuro, como sugerido por Ost (1999), é o caminho indicado. Superar o regime tutelar não só no texto legal, mas também nas práticas administrativas e judiciais é necessário. Diversidade cultural não implica em incapacidade ou limitação, mas em mera diferença. Caminho propício para o futuro, para o "virar a ampulheta" (OST, 1999), é a legitimação processual efetiva dos indígenas e das comunidades indígenas, sem que tenham que adotar soluções jurídicas dos não índios para fazer valer seus direitos.

Para além disso, há muito a avançar no que se refere à diferença dos indígenas, ao reconhecimento de seus valores, crenças, tradições e maneiras próprias de solucionar conflitos. É preciso avançar na formação permanente dos integrantes do Poder Judiciário, de maneira que possam se abrir ao conhecimento acerca da diversidade e do reconhecimento de seu valor, de maneira a contribuir para que o acesso à justiça se efetive cada vez mais aos indígenas.

\section{REFERÊNCIAS}

BERNO, Alexandre Alberto. A legitimação constitucional ad processum dos índios em face do não atendimento dos Direitos indígenas: o direito brasileiro e a Corte Interamericana de Direitos Humanos. Disponível em:

<http://www2.cjf.jus.br/jspui/bitstream/handle/1234/43163/Berno,\%20Alexandre\%20Alberto. pdf? sequence=1> . Acesso em 10 nov 2013.

BRASIL. Comissão Nacional da Verdade. Relatório: textos temáticos. Brasília: CNV, 2014. Volume II. Disponível em: http://www.cnv.gov.br/. Acesso em 22 set. 2020.

BRASIL. Constituição da República Federativa do Brasil. Disponível em: 
http://www.planalto.gov.br/ccivil_03/constituicao/ConstituicaoCompilado.htm. Acesso em: 13 out. 2015.

BRASIL. Lei n. 3.071, de 01 de jan. de 1916. Código Civil dos Estados Unidos do Brasil. Disponível em: http://www.planalto.gov.br/ccivil 03/leis/13071.htm. Acesso em: 10 set. 2020.

BRASIL. Lei n. 6.001, de 19 de dezembro de 1973. Dispõe sobre o Estatuto do Índio. Disponível em: http://www.planalto.gov.br/ccivil_03/leis/16001.htm. Acesso em: 09 dez. 2013.

BRASIL. Lei n. 7.347, de 24 de julho de 1985. Disciplina a ação civil pública de responsabilidade por danos causados ao meio-ambiente [...]. Disponível em: http://www.planalto.gov.br/ccivil_03/leis/17347compilada.htm. Acesso em: 23 set. 2020.

BRASIL. Decreto n. 5.051, de 19 de abril de 2004. Promulga a Convenção n. 169 da Organização Internacional do Trabalho - OIT sobre Povos Indígenas e Tribais. Disponível em: http://www.planalto.gov.br/ccivil_03/_ato2004-2006/2004/decreto/d5051.htm. Acesso em: 09 dez. 2013.

BRASIL. Supremo Tribunal Federal. Petição n. 3.388. Relator: Ministro Carlos Ayres Britto. Brasília, 19 mar. 2009. Disponível em:

http://www.stf.jus.br/portal/processo/verProcessoAndamento.asp?numero=3388\&classe=Pet

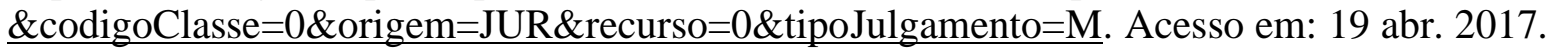

BRASIL. Supremo Tribunal Federal. Ação Civil Originária n. 312. Relator: Ministro Eros Grau. Redator do acórdão: Ministro Luiz Fux. Brasília, 02 maio 2012. Disponível em: http://www.stf.jus.br/portal/processo/verProcessoAndamento.asp?numero=312\&classe=ACO $\underline{\text { \&codigoClasse }=0 \& \text { origem }=J U R \& \text { recurso=0\&tipoJulgamento }=\mathrm{M}}$. Acesso em 27 mar. 2017.

BRASIL. Tribunal Regional Federal da 3ª Região. Apelação cível n. 2004.03.99.0292219/MS. Relatora: Marisa Santos. São Paulo, 23 jun. 2005a. Disponível em: http://web.trf3.jus.br/base-textual/Home/ListaColecao/9?np=2. Acesso em 23 set. 2020.

BRASIL. Tribunal Regional Federal da 3 ${ }^{\text {a }}$. Região. Apelação cível n. 2004.03.99.0300630/MS. Relatora: Marianina Galante. São Paulo, 21 jun. 2005b. Disponível em:

http://web.trf3.jus.br/base-textual/Home/ListaResumida/1?np=0. Acesso em 23 set. 2020.

BRASIL. Tribunal Regional Federal da 3ª Região. Apelação cível n. 2004.03.99.0292712/MS. Relatora: Leide Polo. São Paulo, 04 maio 2006. Disponível em: http://web.trf3.jus.br/base-textual/Home/ListaColecao/9?np=1. Acesso em 23 set. 2020.

BRASIL. Tribunal Regional Federal da 1 a . Região. Apelação cível n. 1997.01.00.0100629/TO. Relator: João Batista Moreira. Brasília, 12 mar. 2007. Disponível em: https://arquivo.trf1.jus.br/PesquisaMenuArquivo.asp. Acesso em 23 set. 2020.

BRASIL. Tribunal Regional Federal da 1 a . Região. Agravo de Instrumento n. 2008.01.00.006925-2/BA. Relator: Cândido Ribeiro. Brasília, 13 abr. 2009. Disponível em: https://arquivo.trf1.jus.br/PesquisaMenuArquivo.asp. Acesso em 23 set. 2020. 
CÚPULA JUDICIAL IBERO-AMERICANA: Raízes comuns, justiça forte e unida.

Disponível em: http://www.stj.jus.br/sites/portalp/Institucional/Relacoes-

internacionais/Cupula-judicial-Ibero-Americana Acesso em: 11 set. 2020.

DALLARI, Dalmo de Abreu. Reconhecimento e proteção dos direitos dos índios. In: Revista de Informação Legislativa, v. 28, n. 111, jul/set 1991. Brasília: Senado Federal, 1991, p. 315-320.

FAZZALARI, Elio. Instituições de direito processual. 11. Ed. Campinas: Bookseller, 2006.

GRINOVER, Ada Pellegrini (Coord.). A tutela dos interesses difusos. São Paulo: Max Limonad, 1984.

IBGE. Instituto Brasileiro de Geografia e Estatística. Os indígenas no Censo demográfico 2010: primeiras considerações com base no quesito cor ou raça. Rio de Janeiro: 2012.

Disponível em: https://indigenas.ibge.gov.br/estudos-especiais-3.html Acesso em: 3 set. 2020. MARINONI, Luiz Guilherme. Teoria geral do processo. 3. Ed. São Paulo: Revista dos Tribunais, 2008.

ORGANIZAÇÃO INTERNACIONAL DO TRABALHO. Convenção n. 169 sobre povos indígenas e tribais e resolução referente à ação da OIT. Brasília: OIT, 2011.

OST, François. O tempo do Direito. Porto Alegre: Instituo Piaget, 1999.

PEREIRA, Deborah Macedo Duprat de Britto. O estado pluriétnico. Disponível em: http://bibliotecadigital.mpf.mp.br/bdmpf/handle/11549/83418. Acesso em 11 set. 2020.

PINTO, Paulo Gabriel Hilu da Rocha. Grupos étnicos e etnicidade. In: LIMA, Antônio Carlos de Souza (Coord.). Antropologia e direito: temas antropológicos para estudos jurídicos.

Brasília / Rio de Janeiro / Blumenau: Associação Brasileira de Antropologia / LACED / Nova Letra, 2012.

\section{REGRAS DE BRASÍLIA SOBRE ACESSO À JUSTIÇA DAS PESSOAS EM}

CONDIÇÃO DE VULNERABILIDADE. Disponível em:

http://pfdc.pgr.mpf.mp.br/atuacao-e-conteudos-de-apoio/publicacoes/direitos-

humanos/Regras\%20de\%20Brasilia\%20sobre\%20acesso\%20a\%20justica.pdf/view. Acesso em: 5 set. 2020.

\section{REGLAS DE BRASILIA SOBRE ACCESO A LA JUSTICIA DE LAS PERSONAS EN CONDICIÓN DE VULNERABILIDAD (Actualización aprobada por la Asamblea Plenaria de la XIX edición de la Cumbre Judicial Iberoamericana, abril de 2018, Quito-Ecuador). Disponível em: https://eurosocial.eu/biblioteca/doc/reglas-de-brasilia-sobre-acceso-a-la- justicia-de-las-personas-en-condicion-de-vulnerabilidad/. Acesso em 22 set. 2020.}


RELATÓRIO FIGUEIREDO. Disponível em: http://www.mpf.mp.br/atuacaotematica/ccr6/dados-da-atuacao/grupos-de-trabalho/violacao-dos-direitos-dos-povosindigenas-e-registro-militar/relatorio-figueiredo. Acesso em: 22 set. 2020.

RELATÓRIO GERAL DO SEMINÁRIO ANÁLISE DAS 100 REGRAS DE BRASÍLIA POR INSTITUIÇÕES DO SISTEMA DE JUSTIÇA DO BRASIL, ARGENTINA, URUGUAI, PARAGUAI E CHILE: o acesso à justiça de pessoas em condição de vulnerabilidade. Rio de Janeiro: ADPERJ, 2009. Disponível em:

http://www.aidef.org/wtksite/cms/conteudo/151/ISO-8859-

1 Relat F3rio Seminario Rio 100 20Regras 20de 20Bras EDlia.pdf . Acesso em 18 nov. 2013.

SILVA, José Afonso da. Comentário contextual à constituição. 6. Ed. São Paulo: Malheiros, 2008.

SOUZA FILHO, Carlos Frederico Marés de. O renascer dos povos indígenas para o direito. Curitiba: Juruá, 1998.

WAGNER, Daize Fernanda. A pena privativa de liberdade entre os povos indígenas do oiapoque: modelo próprio de execução penal? Criminologias e Política Criminal.

Florianópolis: ed. CONPEDI, 2014. Disponível em:

<http://www.publicadireito.com.br/artigos/?cod=0cf5d42e34cfeb8a >. Acesso em: 24 set. 2020 .

WAGNER, Daize Fernanda. A Convenção 169 da OIT e o controle de convencionalidade nos tribunais da região Norte do Brasil. Revista de Direitos Humanos em Perspectiva, v. 6, n. 1, p. $18-37,2020$.

WATANABE, Kazuo. Acesso à justiça e sociedade moderna. In: GRINOVER, Ada Pellegrini; DINAMARCO, Cândido R.; WATANABE, Kazuo (Coord.). Participação e processo. São Paulo: Revista dos Tribunais, 1988. 